\title{
4 STRENGTHENING COMMUNITIES FOR PEACE
}

\section{Bert Jenkins}

In December 1998, Leitana Nehan developed a proposal for their first large project for community peace-building on Bougainville, to be funded by the Australian Agency for International Development (AusAID). The proposal was revised and resubmitted to AusAID in September 1999 as a project entitled 'Strengthening Communities for Peace' (SCP). Leitana Nehan was sponsored in this enterprise by the International Women's Development Agency (IWDA), based in Melbourne, Australia, with which it had worked in the past (see Chapters 2 and 3), and was to be a partner in the project. The project was funded as part of AusAID's Bougainville Reconstruction Program. In accordance with Leitana Nehan's constitution, the project focused on the organisation's main goals, namely, to create a less violent and more peaceful Bougainville, placing specific emphasis on combating violence against women and promoting women's rights. Phase 1 of the SCP project was funded for two years, and launched by the Australian High Commissioner, $\mathrm{Mr}$ Nick Warner, on 24 February 2000.

Phase 1 of the project comprised a variety of community-based peace-building activities, as well as organisational development and training for Leitana Nehan that provided invaluable capacity-building for staff and volunteers as project workers and managers. The main peace-building objective of the SCP project, as outlined in the proposal (LNWDA and IWDA 1999), was to

...strengthen the ability of women, communities, community leaders and Leitana Nehan trainers to address violence in Bougainville in general and violence against women in particular. 
Three main areas of peace-building were addressed by the project: reducing direct violence related to alcohol and homebrew consumption; promoting personal development, particularly Integral Human Development (IHD); ${ }^{1}$ and providing counselling for those affected by trauma. Peace-building aimed to reduce or eliminate violence against women and families, and raise awareness about human rights, women's rights and the negative consequences of alcohol abuse at both the personal and community levels.

Much of the peace-building work was carried out in such a way that it fulfilled the second objective of the SCP, which was to build the organisational capacity of Leitana Nehan. ${ }^{2}$ The fact that Leitana Nehan, with its beginnings as a humanitarian relief operation, had been invited to submit this proposal in 1999 was evidence that major donors and partners considered it ready and able to undertake a major project like SCP. Furthermore, Leitana Nehan proposed to work in partnership with, and under the mentoring guidance of, IWDA, an experienced and well-regarded international women's NGO, with which they had worked successfully in the past. All of the above improved the chances of the SCP project in Bougainville being funded. ${ }^{3}$

In the project proposal, Leitana Nehan provided three reasons why it was an appropriate organisation to carry out the SCP project (LNWDA and IWDA 1999:3). First, Leitana Nehan had already successfully provided a homebrew awareness program funded by AusAID in that donor's NGO Cooperation Program since 1996, also supported by IWDA. This earlier project, 'Working Towards Peace' (WTP), was a forerunner to the SCP project. The SCP project proposed expanding to other parts of Bougainville the awareness workshops conducted successfully under the WTP project, which had focused mainly on homebrew and community violence in Buka, Nissan and Northwest Bougainville. The SCP project also widened the scope of Leitana Nehan's work to promoting awareness about women's rights. This was in addition to addressing the violence against women and families that was directly associated with alcohol abuse and homebrew consumption.

Second, Leitana Nehan argued that it was the right organisation to undertake the SCP project because of its recognition as a successful 
NGO, within Bougainville and internationally. It had a favourable reputation as an agency that could deal effectively with women's development issues and thereby play an important role in post-conflict recovery in Bougainville. ${ }^{4}$

A third justification related to Leitana Nehan's ongoing contribution to peace-building through facilitation of healing at the individual, family and community levels, achieved through its earlier awareness programs. A focus on personal healing, personal development and IHD principles was built into the SCP project to cater for people's spiritual needs. The community radio program that had been broadcast weekly across the region by Leitana Nehan since 1999 had already contributed to increasing awareness about the prevalence of violence and social problems in Bougainville. The SCP project was therefore justified as building on strong foundations laid down by Leitana Nehan's earlier programs and projects combatting cultures of violence.

The rationales used for the SCP project provide a clear indication of the need for the project. It dealt with the common problem of residual violence found in many post-conflict societies. Irrespective of whether they were members of the Bougainville Resistance Forces (BRF) or the Bougainville Revolutionary Army (BRA), ex-combatants' purpose in life and very existence for several years had revolved around armed violence. In post-conflict environments, ex-combatants have difficult adjustments to make. Disposal of weapons, for instance, reduces their power; they may find few employment or training opportunities to help them reintegrate into mainstream society, and post-traumatic stress can also hinder re-adjustment to a peaceful society. Under these difficult circumstances ex-combatants may resort to alcohol and drug abuse, which can lead in turn to violence in the domestic sphere, affecting women, children and families. In Bougainville, where a culture of violence remained after the formal cessation of hostilities, the SCP project offered non-violent means through which peace and harmony could be restored in people's lives, paving the way for post-conflict rehabilitation and recovery at the community level.

The SCP project essentially involved training teams of volunteers to undertake peace-building work in communities (see Appendix 2). 
Before turning to a detailed account of the project, I first describe three other major support programs and a range of minor activities in which Leitana Nehan was involved. These activities enhanced the organisation's capacity and community exposure, provided valuable support for the SCP teams, and contributed directly and indirectly to the project's success.

\section{SUPPORT PROGRAMS}

Three major support programs contributing to Letiana Nehan's peacebuilding objectives were undertaken simultaneously: a radio program, a counselling service and a theatre troupe. These programs were coordinated predominantly through Leitana Nehan's main office in Buka.

Commencing in 1999, the radio program disseminated information and increased awareness about homebrew, violence against women, and women's rights. ${ }^{5}$ The radio program complemented the awareness workshops and other field activities that the teams were busy carrying out across Bougainville. It was a popular program, with anecdotal evidence indicating that many people listened on a weekly basis. It served to highlight the work being conducted by the teams at various localities and thus helped to reduce violence in many communities. It also promoted communication between local communities and the field teams about social problems that needed urgent attention (see Appendix 5).

The counselling service provided not just counselling but also basic legal advice to victims of rape, incest and domestic violence, with the aim of empowering women to move out of abusive domestic situations where necessary. A handful of counsellors associated with the organisation had sufficient training to undertake this difficult task. As noted earlier, Helen Hakena, Bianca Hakena and Elizabeth Behis had attended training programs in basic counselling, feminist counselling and legal literacy at the Fiji Women's Crisis Centre, while Alina Longa, one of the Leitana Nehan founders who worked for Catholic Family Life, also provided counselling services. However, they were all based in Buka and worked mainly at the Leitana Nehan office, where renovations had been made to accommodate counselling in a private space designed for this purpose. 
Leitana Nehan had planned initially for counsellors to spend up to eight weeks per year travelling to various parts of Bougainville to offer counselling services to women in the more remote areas. It turned out that it was not feasible or efficient for occasional trips by trained counsellors from Buka to meet the regular demands for counselling faced by the field teams. The fact that counsellors were expected to produce monthly counselling records and three-monthly data reports indicates the planned frequency of activity. Regular visits were not a practical or viable proposition under the circumstances in Bougainville, especially because of high transport costs, which would have strained the budget, and other substantial communication constraints (LNWDA 2000a). It was necessary, therefore, to train counsellors who could work in the districts alongside the teams. ${ }^{6}$ These mobile field counsellors kept records, helped people as much as they were able and identified people who needed advanced counselling, whom they referred to the central counselling facility at the Leitana Nehan office in Buka. The team counsellors identified individuals and families that needed counselling and/or legal support and reported these needs to the Leitana Nehan office in Buka for action by the more experienced counsellors based there. It was expected that counselling statistics and records would be used to plan Leitana Nehan's media and community awareness activities, and also to lobby for policy reforms and improved services for women and families that needed special attention during the traumainfluenced post-conflict period. Nevertheless, it was difficult to expect immediate attention to demands for government action and policy changes in a situation in Bougainville where governance was a complex combination of provincial, local and PNG administration.

Leitana Nehan staff members were aware that counselling was not something that Leitana Nehan could or should carry out on its own (LNWDA and IWDA 1999), at least partly because the organisation had only a few counsellors sufficiently trained to carry out the work. According to the proposal, the teams would not be specifically involved in trauma counselling themselves but team members were to be trained as informed fieldworkers who understood the context and sensitivities surrounding their activities in relation to post-traumatic stress and how this had affected both individuals and communities following the conflict. 
Counselling was required for males as well as females. In one case, for example, a boy had been mute for seven years as a result of witnessing attacks on his relatives. Helen counselled him that it was not his fault; he was only very young at the time of the attacks, and he did not have power to stop it. Then he burst out crying and spoke for the first time since the attacks, saying it was true; he had blamed himself for not being able to help them. He said that if he had been bigger, he would have killed the attackers.

By the end of Phase 1 of the SCP project, Leitana Nehan was aware that the demand for counselling at the community level was greater than anticipated. Although many social problems were identified during SCP 1, meeting this demand for counselling was largely beyond the scope of the project; more funds were needed to train a number of field-based counsellors to address the many and varied social problems that existed in the communities. Leitana Nehan realised that the counselling skills that were called for in the communities were more than IHD alone could address.

The Hihatuts Theatre Troupe played a key role in supporting the field teams by reinforcing the messages broadcast on the radio and through the print media regarding social problems and violence in communities. They did this creatively through village or street theatre. Hihatuts specifically assisted Leitana Nehan in increasing awareness about highly sensitive issues relating to rape, incest and domestic violence, which were commonplace in some communities but too confronting to address directly. Some community leaders were reportedly reluctant to allow Leitana Nehan to conduct workshops because of the possibility that they would raise very sensitive issues and expose, inadvertently or otherwise, the individuals responsible, prompting greater community instability. In these difficult circumstances, the troupe was instrumental in drawing victims of violence into dialogue with team leaders and Leitana Nehan counsellors, thereby enabling the teams and community representatives to deal with these problems sensitively or alert authorities when and where it was appropriate to do so. 


\section{OTHER ACTIVITIES}

On 6-8 March 2000, Leitana Nehan organised International Women's Day celebrations, which also involved a peace march by 300 women in Buka. ${ }^{7}$ Two days prior to this, Leitana Nehan held a workshop on violence against women, attended by many women from all over Bougainville, where they discussed gender issues, safe motherhood and HIV/AIDS (LNWDA n.d.).

Leitana Nehan organised a multi-sector workshop for NGOs working in Bougainville and the rest of Papua New Guinea at the end of May 2000 to discuss development needs in the region (LNWDA n.d.). This event shows how Leitana Nehan was increasingly taking the lead in organising development strategies with other NGOs in the region.

At the end of June 2000, Community Aid Abroad/Oxfam Australia visited Leitana Nehan to strengthen their relationship with the

\section{Box 4.1 Dramatic experiences for the Hihatuts Theatre Troupe Fabian Kotsin}

The reason we started the theatre group was because of illiteracy. Plenty of kids missed out on school and didn't understand issues in the awareness program. So we decided to make a theatre group to make it easier to communicate with these youth who were illiterate. It was easier to communicate the ideas using actions, especially when they don't speak tok pisin.

I am the director of Hihatuts, and I was the founder. The other founders were Ezekial Lames and Quentin Hotsia. One time we went up to Wagog, in Tinputz district. We were doing the awareness program and a boy stood up and he said, 'these people are lying to you. I am a frog, I can drink. I can prove it by drinking this bottle!' He had a $350 \mathrm{ml}$ Coke bottle of pure homebrew, and he started to drink it. When he had drunk half of it, he collapsed. They took him to the hospital in Tinputz but the PNG doctor said they had no treatment for alcohol poisoning, so they set off for the hospital in Buka, but he died on the way.

Another time we performed at a place on the other side at Kokopau, They were having games and we went to entertain them. Then we started performing one of our plays. In the play, I started to sing about children and women, and the kinds of violence they experience at home. The song is actually about children's rights. The crowd was so moved by this song, called 'the dream', that by the time I finished, many people in the crowd were in tears. 
organisation and plan a youth development project (LNWDA n.d.). The visit led to a project, subsequently funded by CAA, to run youth development workshops in Bougainville, the first of which-on Youth Capacity Building - was held in Buka in August 2000 (LNWDA 2001a:8-9). Thirty young people attended the workshop, which was based on the premise that youth empowerment is the key to youth development (LNWDA 2001a:9). The main purpose of this training was to prepare young people to work more effectively in organisations and to provide them with basic management and organisational skills. The organisational development skills learned at the workshop were essential for young people who were interested in working for an NGO or setting up community-based organisations (CBOs). As Buka became the administrative centre in Bougainville during and following the crisis, many people including youth had moved there in the hope of gaining employment. All of the topics covered during the training in Buka were relevant in the context of developing and administering CBOs in rural areas. ${ }^{8}$ The establishment of $\mathrm{CBO}$ s later became one of the objectives of SCP Phase 2, under the umbrella of community development and particularly organisational development. A monitoring and evaluation exercise carried out by project officers at a one-day workshop in Buka in November 2000 determined that 90 per cent of the young people who had participated in the August training session were applying the skills they had learned in their respective workplaces (LNWDA 2001a:9).

Apart from establishing the SCP project in 2000, Leitana Nehan was simultaneously supporting the establishment of other women's organisations on Bougainville. For example, Agnes Titus, with funding and training support from Helen Rosenbaum and Annie Goldflam from IWDA, organised and ran a capacity-building workshop for the Siwai District Women's Council (LNWDA 2001a:12). The workshop was held in Tonu in the south of Bougainville from 28 September-6 October 2000. The workshop aimed to facilitate strategic planning, which involved developing a vision and strategic plan as well as furthering the understanding of organisational roles and responsibilities. It also sought to develop organisational programming skills with respect to project planning, implementation and management, as well as monitoring and reporting. 
This approach to community development demonstrates Leitana Nehan's mentoring and facilitation role in support of the organisational development of a women's $\mathrm{CBO}$ in the far south of Bougainville, far removed from the administrative centre in Buka. Leitana Nehan's contact in Siwai was Anne Rangai, who was also a graduate of Asitavi High School, and who was the informal coordinator of women's activities in the Siwai district administration. When Agnes and her team arrived to conduct the workshop, they found a circular from the Minister of Women's Affairs of the Bougainville Interim Provincial Government, ordering district officials to cease all involvement with Leitana Nehan on the grounds that the BIPG had not been officially informed of the workshop. District officials, however, had been informed and approved of the workshop, so the Leitana Nehan team ignored the BIPG directive and went ahead with their program. The women who participated so appreciated the workshop that they gave each of the presenters six pieces of the basketware for which the area is famous (so-called Bukaware) as gifts, and even sent other gifts at a later date. This example of a liaison with a women's organisation in the south later helped Leitana Nehan in extending its work through SCP in a part of Bougainville more remote from its centre of influence in the north.

The second workshop for youth, funded by CAA, was held in Tinputz from 3-8 December 2000. It focused on 'youth mobilisation' and was attended by 83 people, of whom 63 were youth (LNWDA 2001a:910). The aims of the Tinputz youth training were somewhat different to those for the Buka training in that they concentrated more on peacebuilding and conflict transformation, particularly establishing, reorganising and strengthening the young people's work; bringing young people together as a means of promoting peace, unity and reconciliation; empowering young people to identify the roles they could play in rebuilding their lives in Bougainville, in a post-conflict situation; encouraging young people to understand fully the importance of their cultural heritage; and guiding young people to access the information they needed to pursue their own personal enrichment.

The Tinputz workshop demonstrated a need in the district for young people to reflect on, and learn about, peace and reconciliation following the crisis, since during that time there had been much conflict between 
groups of youth affiliated with either the Bougainville Revolutionary Army or the Bougainville Resistance Forces in the area. The workshop enabled young people to express their views about issues affecting the peace process and development in Bougainville (LNWDA 2001a:10). The subjects covered during the workshop included personal relationships, gender awareness, family life, trauma counselling, HIV/AIDS awareness, community policing, the role of the Peace Monitoring Group (PMG), and youth participation in peacebuilding and development projects (LNWDA 2001a:10). It is obvious that many of these topics are directly relevant to the SCP project and the general objectives of reducing violence in society and violence against women. From a different perspective, both the youth training programs in Buka and Tinputz were aimed at getting young people to consider how to rebuild their lives constructively. The more destructive paths that young people could follow in post-conflict Bougainville included formation into groups that instigated violence and crime or engaged in illegal activities such as the brewing and drinking of alcohol, which in turn could lead to violence or crime. The youth workshops demonstrated constructive pathways for young people as alternatives to crime and violence.

At the same time as the SCP project was getting off the ground in 2000, Leitana Nehan was involved in a number of projects associated with peace-building agendas that involved awareness training workshops, meetings and advocacy, especially in relation to gender awareness and women's rights (LNWDA 2001a:10). ${ }^{9}$ Apart from AusAID funding for the SCP project, in 2000 Leitana Nehan obtained over K95,000 in funding for a range of small projects, from donors including the PNG Community Development Scheme, CAA Oxfam, the New Zealand High Commission, IWDA and the Asian and Pacific Development Centre (LNWDA 2001a).

In 2001, Leitana Nehan continued its role of supporting other women's organisations, even though a large proportion of its time was devoted to the implementation of SCP Phase 1. Helen Hakena and George Lesi ran a capacity-building workshop in Buka, which was attended by 20 women and focused on the organisation and management of a CBO (LNWDA 2002a). The women received 
training in project management, project planning and meeting procedures. George Lesi and Agnes Titus later repeated the workshop on Nissan for women's organisations on the atolls.

Besides its facilitation role in empowering other women's organisations, Leitana Nehan was involved in training people in the area of women's health. For instance, Leitana Nehan organised a training course on 'village birth attendance' from the 10-22 September 2001 for 46 women. The course, funded by the Australian Alliance for Reproductive Health (AARH), was conducted by Aloysius Pukiene and Maggie Kenyon (from AARH) and aimed to reduce the number of mothers and children dying during childbirth, a major problem in Bougainville.

Some of Leitana Nehan's activities were not at all related to donorfunded projects. For example, in September 2000 Leitana Nehan was instrumental in organising and participating in a march organised by the Buka District Council of Women to muster public support for the peace process. The women specifically asked for an ongoing commitment to the ceasefire and Buin peace declaration; the leaders in Bougainville and Papua New Guinea to continue negotiating to reach a lasting peace agreement; the protection of private and public property; and a policy of zero tolerance for any form of violence (LNWDA n.d.). The women presented a petition in support of the peace process to Governor John Momis, who represented the Bougainville Interim Provincial Government, and to the President of the Bougainville People's Congress, Joseph Kabui. In this way, Leitana Nehan was active in advocacy and in empowering women to influence the peace process in a positive way. The women's march on 13 September followed the sixth political negotiations for peace between the PNG national government and Bougainville leaders. The negotiations took place in Rabaul between 4-6 September 2000 to discuss details about autonomy for Bougainville, the referendum for independence and arms disposal.

On 23 December 2000, Leitana Nehan was notified that it had been selected as a winner of the Millennium Peace Prize for Women. This joint initiative of the United Nations Development Fund for Women (UNIFEM) and International Alert (LNWDA 2001a) awarded three 
prizes to individuals and three to organisations. The cash component of the prize was placed in a UNIFEM account to be accessed by women's groups around the world. The prize was international recognition for the peace work that Leitana Nehan had carried out. Helen, Brenda Tohiana, Celine Kiroha and Anne Harepa travelled to New York in March 2001 to receive the award. On the morning of the award ceremony, Helen was surprised to receive a telephone call from UNIFEM, asking her to represent the women of the world in delivering to UN Assistant Secretary General Angela King a petition containing 350,000 signatures calling for greater participation by women in all peace-building processes.

In addition to the activities described above, the leadership of Leitana Nehan, including Helen as executive director and George as deputy executive director, contributed in a number of other ways to improving the profile of the organisation in the period 2000-04 when the SCP project was underway. Helen travelled widely to promote Leitana Nehan and to learn about peace issues in the international arena of post-conflict peace-building. In October 2000, she attended a peace symposium at Parliament House in Canberra, Australia and a workshop at the Australian National University on 'Conflict and Peacemaking in the Pacific' (LNWDA n.d.). Helen returned to Australia in April 2001 to attend a 'Small Arms and Conflict' workshop held in Brisbane. In July 2001, Helen spoke at the United Nations in New York on the suffering of women in conflict and post-conflict situations and at the UN conference on 'Illicit Trade in Small Arms and Light Weapons' (LNWDA 2002a).

Helen Hakena is also an accomplished facilitator and trainer. She is often called on to act in this role for Leitana Nehan and other organisations. For instance, Helen conducted training for police personnel in September 2001 on the topics of gender awareness and basic counselling to help them develop appropriate skills when dealing with clients (LNWDA 2002a). ${ }^{10}$ This approach to training personnel in government agencies was expanded further in Phase 2 of SCP.

Helen also underwent leadership training and professional development by joining women leaders in peace-building at different training conferences. For example, in November 2001 she attended the 
'Facilitation and Conflict Transformation' workshop in Fiji, which was run by the Eastern Mennonite University from the United States. She also participated in the 'Women Peacemakers Program', which was organised by the International Fellowship Of Reconciliation. She participated in one such workshop in Oxford in 2002 and a second workshop, on the adoption of 'non-violent conflict resolution' strategies, in Timor Leste in 2004 (Hakena 2004).

George Lesi was the deputy director of Leitana Nehan during the SCP project. He had been the Chief Administrator of the Bougainville province of Papua New Guinea and hence was well versed in the areas of governance, organisational development, project management, project design and project programming as well as monitoring, evaluation and reporting. George was also called upon to conduct workshops or to review programs in organisations other than Leitana Nehan. In 2001, for example, he conducted a review for the Rabaul Archdiocese and facilitated capacity-building workshops for the AusAID-funded Community Development Scheme (CDS) in three provinces of Papua New Guinea.

Other Leitana Nehan staff and volunteers were also involved in a range of activities outside of the formal confines of SCP Phase 1. As noted earlier, Leitana Nehan was a founding member of the Pacific Violence Against Women Network. They continued their involvement during this period of their history by sending Agnes Titus and Fabian Kotsin to Pacific Violence Against Women Network workshops in Fiji in 2001.

\section{SCP PHASE 1 PROJECT DESIGN AND ORGANISATION}

The SCP project involved selecting and deploying 10 teams of volunteers to conduct community awareness workshops in the areas of homebrew, violence prevention and IHD. Each team initially had five members, including a team leader and four project volunteers. At least one or more of these volunteers were women. Team members were selected on the basis of their willingness, experience and skills. Members received a per diem payment for their work only when they were engaged in an activity with a local community group or involved in training or reporting. The plan was to deploy eight teams 
on the main island of Bougainville, one team on the island of Buka, and another team on Nissan and nearby atolls. Two project officers coordinated team activities. Andrew Goman was originally responsible for the teams the North (Nissan, Buka, Selau/Suir, Tinputz and Northwest), and later this responsibility was assumed by Hilary Laris, and then Rose Trongat. Rose had taught Agnes, Helen, Brenda and Alina at Asitavi High School, was later employed to cover IHD training for volunteers and community representatives. Benedicta Noneng was the project officer responsible for teams in the South and Central parts of Bougainville (based in Wakunai, Paruparu, Buin, Siwai, and Bana). As the work developed, Benedicta became responsible for the teams in the central area, while Anne Rangai coordinated the teams in the south.

Each project officer had specific administrative tasks within Leitana Nehan. They were responsible for organising workshops for the teams and leaders, coordinating volunteer trainers for workshops, reporting on project activities and producing field manuals. They were also involved in producing support materials and providing advice and general support for the teams. However, the project officer responsible for the teams in South Bougainville, Anne Rangai, was later trained as a counsellor in Fiji and hence had dual roles to play in her interactions with the teams and volunteers. Anne's training in counselling made sense because of the isolation of these districts from Buka, where the other counsellors were based.

The project concentrated on three major activities and three support programs in relation to the primary objective of building peace at the community level (LNWDA and IWDA 1999).

\section{PROJECT ACTIVITIES}

\section{Awareness workshops on homebrew and violence}

Awareness workshops were conducted for over 120 community groups, including schools, spread over the main island of Bougainville, the island of Buka, and on Nissan and the other atolls. The workshops aimed to increase awareness of health and community effects of homebrew alcohol and its links to violence in the community. The 
types of violence addressed included various community disputes and family problems (marital problems, rape, incest, child abuse and financial difficulties). Discussions during an initial one-day community workshop identified key issues for each community and prompted the community to hold further meetings to address their own social problems. This process increased the number of participants in follow-up workshops carried out by the teams to target the issues identified by the communities. In addition, the teams encouraged communities to formulate their own solutions to local problems. In many cases, the workshops, meetings and discussions helped local communities develop strategies that would reduce alcohol-related violence and other social problems, and reduce the production and consumption of homebrew.

The awareness workshops were linked to the IHD workshops described below under the second major activity of the project, in which a number of volunteer 'community representatives' were trained to work in their own communities. These community representatives functioned as a link between Leitana Nehan field-teams and members of each community. The local communities were involved in selecting their community representatives using criteria developed by Leitana Nehan. The teams assisted with this selection process during or soon after the initial awareness workshop. The teams trained community representatives in how to engage with their own people in raising awareness about social problems; organise gatherings to discuss issues; identify individuals who need counselling; and devise strategies to reduce violence in the community. The follow-up workshops concentrated on fine-tuning local strategies for violence prevention with local input from the community representatives. By working together they were able to try new initiatives and monitor changes in behaviour and record incidents of violence between workshops, thereby catering for the specific needs of each community.

Community representatives played an important role in developing strategies to end violence at a local level. The field teams supported their endeavours to address the root causes of social problems that had led to local conflicts. In addition, the teams planned to organise the community representatives into a network as a means of 
empowering them to support each other. However, despite their best intentions, the teams were not in any position to train the community representatives beyond basic empowerment and facilitation functions. The community representatives needed more training to carry out the work that the teams had commenced in their local communities. This was difficult to achieve without additional funding. Furthermore, the teams would have had to spend a lot more time in the districts if they were to reach every village on Bougainville in ongoing workshops. Such coverage was beyond the scope of SCP.

\section{Training in IHD techniques for the community representatives}

IHD workshops were planned in order to train the volunteers and community representatives in a very basic form of counselling. Community representatives were trained in the essentials of applying IHD at an intensive workshop that followed the initial awareness workshops in communities. The aim of this activity was to establish a network of local community representatives who could support each other to be effective in their respective communities beyond the life of the project. They were trained to apply IHD principles in addressing violence and social problems through the avenues of personal development and individual healing (Byrne 1983). Leitana Nehan readily acknowledged their Roman Catholic influence (see also Chapter 6). Therefore, IHD was the accepted grassroots vehicle of the SCP project in the bid to eliminate violence at the local community level in Bougainville. In the project proposal, Leitana Nehan and IWDA (1999:10) provided the following description of IHD workshops for training community representatives.

The IHD workshops would explore the wide range of factors that cause violence and disharmony in the community, including anger, grief, fear, trauma, and lack of self understanding, lack of self worth and insufficient guidance/direction for young people. Through analysis and reflection, the workshops aimed to equip the community representatives with the tools to facilitate psychological, emotional and spiritual rehabilitation, and to motivate communities to address their social problems creatively.

Community representatives who participated in IHD training went 
on to plan and conduct IHD meetings for community groups as well as one-on-one IHD counselling sessions with individuals to help resolve social problems and reduce violence. This was not as effective as having fully trained field counsellors but it was the best that could be done at the time. The community representatives' main role was to empower communities to work at identifying and analysing their social problems, and mobilise them to develop strategies that would reduce the incidence of violence. It was hoped that this process would lead to the resolution of local conflicts and build social cohesion, thereby reducing the chance of further violence in society. The community representatives were encouraged to work together by holding joint workshops, sharing information and experiences and debriefing each other, strengthening their collective efforts through networking. These unpaid volunteer community representatives were perhaps the most important players involved in local grassroots peacebuilding. The Leitana Nehan field teams facilitated their local efforts and wherever possible provided limited capacity-building. Apart from this, they had to depend on their local networks and basic training in IHD. The project officer employed in the second year of Phase 1 specifically concentrated on training volunteers and community representatives in IHD as well as providing training and support for IHD in the 10 districts. The question remains whether IHD by itself was sufficient to deal with the social problems that the teams uncovered and experienced in communities across Bougainville.

\section{Training of trainers workshops for teams}

The teams of Leitana Nehan volunteers were trained during three training-of-trainers workshops conducted at different stages of the project to coincide with the community awareness workshops, the initial workshop and consecutive follow-up workshops. This training process was timed to prepare teams prior to their work in the villages and schools and to incorporate changes based on lessons learned when planning subsequent activities. Thus the training-of-trainers workshops provided invaluable preparation for planned field activities. Each workshop ran for two weeks. More time, however, was spent on training team leaders than on training other team members. The 
first week of a training-of-trainers workshop was generally devoted to engaging only with team leaders and their assistants, while entire teams were present in the second week.

The training-of-trainers workshops aimed to train the 10 teams to carry out planned activities with community groups. These activities included the initial awareness workshop, up to two followup workshops, and various other interactions with community representatives and local leaders. The training-of-trainers workshops involved 10 team leaders and 40 volunteer assistants in Phase 1. Training in the workshops focused on the main activities of violence reduction and IHD. Participants were trained to provide useful follow up support to community representatives, monitor local activities and report on outcomes and lessons learned. They were trained in gathering feedback on the impacts of each workshop, collating information about each community and situation, and collecting and recording information for reports that project officers and the directors compiled for the donor and mentor agencies. The workshops were also intended to gather information to produce a training manual to aid teams in their field activities. The manual was updated over the duration of the project as new experiences and understandings informed the teams' practice.

Community development skills were addressed in the workshops to enhance effective interactions with community groups. The workshops prepared team leaders and volunteers to organise and conduct workshops, make confident presentations to community groups, and trained them in ways to approach, consult and liaise with community leaders. They were also trained in motivating community groups to develop local strategies, reduce violence and act decisively in addressing their social problems. In addition, they were trained to work efficiently in teams. For example, the teams were trained in how to include women in active roles and how to facilitate discussions on sensitive or contentious issues when these matters arose.

Specific topics covered in the workshops included IHD, gender analysis and equity, homebrew awareness, violence against women, women's rights, children's rights and conflict resolution (LNWDA and IWDA 1999). Experienced local trainers were selected to conduct the 
workshops. Accordingly, the workshops covered different aspects including drug and alcohol abuse, HIV, family life issues, trauma and IHD counselling (LNWDA and IWDA 1999). A workshop was carried out in May 2000 (LNWDA 2000b) at the beginning of SCP Phase 1, and another refresher course was conducted in April 2001 for team leaders and one assistant from each team (LNWDA and IWDA 2001; LNWDA 2002b). In addition, basic training was provided to team leaders at a strategic planning workshop in the first quarter of 2000, which was at the very beginning of Phase 1 SCP. The project officers were responsible for organising the workshops in SCP.

\section{CHALLENGES ENCOUNTERED IN THE SCP PROJECT}

At a time of great risk and scarce resources, Leitana Nehan was one of the few active local organisations during the Bougainville crisis, but most of their efforts were restricted initially to working with people in the care centres in PNG government controlled areas (see Chapter 2). During the same period, another organisation, the Bougainville Community Based Integrated Humanitarian Program (BOCBIHP), had begun operating in a similar capacity ${ }^{11}$ in areas that were not controlled by the PNG government. In order to expand their work in SCP 1 to other parts of Bougainville, Leitana Nehan initially had to broker an agreement to work together with BOCBIHP (LNWDA and IWDA 1999). This agreement was possible and widely supported in the northeast, south and central parts of Bougainville as a result of visits to the no-go zone made by Leitana Nehan team leaders and exBRA operatives Ezekial Lames and Francis Botsia in 1999. A subsequent agreement to carry out the SCP project in the central parts of Bougainville enabled Leitana Nehan to recruit project staff and volunteers from these localities and others in the central district where the BRA had more influence on local people during and soon after the conflict. Leitana Nehan faced a major challenge in extending their work from the north, where they had considerable influence, to cover the whole of Bougainville. It is therefore not surprising that the pace with which the organisation could implement its programs varied across districts.

Access into communities was usually straightforward for Leitana 
Nehan in the central, southern and western districts. In a very few cases, chiefs or other organisations carrying out humanitarian work or community development were initially reluctant to support Leitana Nehan's work. In these situations, community members and the people who could see a need for the work that the teams were proposing would invite them into the community, accommodate them and feed them. In most of these cases, the community leaders and the other organisations eventually came around to seeing Leitana Nehan's work as important and relevant. For example, Leitana Nehan received an invitation to work in Gohi village, even though another NGO was working in the area. As a result of one of the youth mobilisations at Hahela, attended by Gregory Manau, the former BRA commander in Tinputz, and Francis Kera, another ex-BRA member, Leitana Nehan was invited into the Tinputz area. Gregory and Francis later became Leitana Nehan volunteers and helped implement the work in that area.

There were seven teams present at the initial strategic planning workshops conducted during Phase 1 of SCP in April 2000. A team from the northwest, Kunua/Kereaka, attended the first training-oftrainers workshop in May 2000 but was replaced later by a collective northwest team. The initial eight district teams in SCP Phase 1 were from Nissan, Buka, Selau/Suir and Tinputz (all in the northern region of the province), Paruparu and Wakunai (central region), and Siwai and Buin (southern region). These initial eight district teams were the most active in SCP overall and remained active until the end of the project.

Leitana Nehan faced two political hurdles in extending its work from Buka throughout the main island of Bougainville. First its name means Buka (and) Nissan, and it was therefore not immediately associated with Bougainville island itself. Second, there were perceptions among some people on mainland Bougainville that people on Buka had sided with the PNGDF during the crisis, and this created a degree of suspicion. However, a number of historical events and cultural traditions contributed to the acceptance of Leitana Nehan in the central and southern districts of Bougainville. These included a strong relationship and commitment to reciprocation of 
goodwill that exists among the chiefs across Bougainville. For example, the chiefs of Siwai came to Buka for refuge during difficult times in the early 1990s and were accommodated by Helen and Kris Hakena. This act of goodwill and friendship helped Leitana Nehan when they were establishing SCP in the south. In another example, Leitana Nehan was instrumental in sending essential items such as stretchers and medicines to the Morotona hospital in the south during the mid 1990s blockade (see Chapter 3). In another case of assistance, Leitana Nehan provided BRA representatives with clothing so that they could dress appropriately to attend peace talks in 1996 (see Chapter 3). In relation to establishing the Paruparu team, it was necessary for Helen Hakena, as executive director, George Lesi, the assistant executive director, and Hilary Laris, one of the project officers (now a member of the Autonomous Bougainville Government), to conduct an intensive awareness workshop for the chiefs from villages in the mountainous areas of the northeast and areas surrounding Paruparu before they could be convinced to support the SCP project. Once this intervention had been carried out, the Chiefs from these areas proceeded eagerly to select their own team members and requested Leitana Nehan to train them, which they did.

Personal and family links were also instrumental in facilitating the work of Leitana Nehan in the central, southern and western districts. For example, the executive director's uncle was married to a woman from Wakunai and another relative had married a woman from the northwest. These links through marriage led to extended family relationships that facilitated exchanges and visits, which in turn enabled Leitana Nehan to get a stronger foothold in these distant districts for their peace-building work. In another situation, a teacher from Koromira/Koianu who had worked with Helen Hakena for several years helped Leitana Nehan to introduce programs into the area. In southeast Bougainville, community leaders in Manatai/Torau had heard how good the Leitana Nehan programs were from the Paruparu experience and hence invited Leitana Nehan to field a team in their area as well. These examples demonstrate how personal and familial relationships between people in Buka and people in other districts helped Leitana Nehan successfully overcome the challenges 
it faced in extending the SCP project across the mainland.

Furthermore, one of the Leitana Nehan team leaders in the central district, John Ibouko (Joseph Kabui's first cousin), who had been a commander for the BRA in the same area, used his influence to promote Leitana Nehan's work. John had been shot in the face while with the BRA in the mountains in the early 1990s. His comrades carried him down to the coast, from where he took a boat to Taro Island in the Western Province of Solomon Islands. From there he was moved to the hospital in the Solomons capital, Honiara, where he spent five years and underwent several operations to reconstruct his face. After the war, he joined Leitana Nehan and became one of its most powerful advocates in his district. He was so keen on Leitana Nehan's model of community development that he was instrumental in starting Darenai school in his district and became the first chair of the school's board of management.

\section{ADVANCING THE PROJECT}

During their first year in the field, the Leitana Nehan teams concentrated their efforts on homebrew awareness, combating violence against women and promoting women's rights, while IHD and counselling were the main focus in the second year (LNWDA 2002a). Each team aimed to visit ten communities, including a number of schools. By September 2000, the teams had conducted initial workshops in eleven schools and eleven communities (LNWDA 2000c). Through these awareness workshops, they came into contact with over 4,500 people, of which over 2,100 were women. Heavy rain was reported to have prevented the teams in Wakunai, Bana, Siwai and Buin from carrying out their awareness workshops by this stage (LNWDA 2000c), and crocodiles (see Box 4.2), armed men, transport difficulties and distance (see Boxes 4.3 and 4.4) also hindered their efforts.

As noted above, Rose Trongat, a specialist IHD trainer, was recruited as a project officer for the SCP. In the second year of the project she ran six IHD training sessions for community representatives in the three regions (south, central and north), including three follow up workshops in Buka. Community 
representatives and volunteers in or near Buka could access the services of the Marist Brothers and Family Life, both of which were associated with the Catholic Church and were able to provide IHD training. Although Leitana Nehan planned to hold regular IHD workshops for the community representatives, this was not feasible given the high cost of bringing representatives from over 120 communities to Buka, and it proved more viable to appoint a roving project officer to deliver IHD training in the districts. Nevertheless, 27 volunteers were brought to Buka for IHD training in the last quarter of 2000 (LNWDA, n.d.), ${ }^{12}$ and a further 20 people were trained in Buka in the third quarter of 2001 (LNWDA 2002b). By the end of Phase 1, one or two volunteers had been trained in IHD on each team. The volunteers, and particularly the team leaders, attended regular planning and review workshops, which enabled Leitana Nehan to collect reliable data for quarterly reporting and to facilitate project implementation.

Leitana Nehan intended to find funds to send several people to Fiji for four weeks of intensive counselling training at the Women's Crisis Centre in Suva. By the end of the first year of Phase 1, Buin, Paruparu and Siwai were recognised as districts that needed counsellors (LNWDA 2001a). The overall plan was to deploy counsellors with at least basic training to a number of districts, preferably to the very areas from which they had originally come. These field counsellors could then work as mobile counsellors alongside the Leitana Nehan teams. Volunteers were selected for this purpose from areas where counselling needs were highest and also from areas that were distant and difficult to reach from the centre in Buka. This training eventually took place in May 2001 when seven counsellors were trained over four weeks in Fiji. Leitana Nehan was now in a position to deploy field counsellors to Nissan, Northwest, Tinputz, Paruparu, Buin, Siwai and Bana districts (LNWDA 2002a). Of the seven counsellors trained in Fiji, Anne Rangai, from Siwai, was also the project officer responsible for the southern Leitana Nehan teams.

By the end of March 2002 the 10 Leitana Nehan teams and 70 volunteers involved in implementing SCP Phase 1 had completed all the initial workshops for 150 communities and follow-up workshops 
for 60 communities and 25 schools (LNWDA 2002b). By this stage, Leitana Nehan had reached 4,934 people, of which 2,762 were women. In a letter to IWDA, Helen Hakena acknowledged the general difficulties faced by project workers during SCP phase 1. She wrote,

[t]he organisation acknowledges the worthy contributions by volunteers, project officers, and experienced trainers. These people have walked hundreds of kilometres on foot, climbed rugged terrains, crossed flooded rivers and braved all sorts of weather, while carrying out Leitana Nehan's complex range of programs. Working in a hostile environment can be risky. The lack of a stable infrastructure like transport, communication, food supply, economical and political issues have all impacted on the SCP Project (LNWDA 2002b:n.p.).

A story in the same document indicates how delicate some of the problems were at a local level for action-oriented peace-builders. In answer to the question 'What did local people tell about their personal situations?' the following response was received.

Three ex-combatants' wives were shot with arms after the consumption of homebrew. Threats have been issued to families when trying to resolve the matter. Communities cannot do much, especially when arms are involved in settling disputes. This alone causes a lot of fear, mistrust, insecurity and foremost instability. Almost in every community visited, Chiefs, women, men and children in schools have all discussed this fear. Fear of retaliation...when ex-combatants die by violent means, causes paralysis to the communities (LNWDA 2002b:n.p.).

\section{Box 4.2 Waking up to a shock Valentine Tur}

Although I usually worked on Buka, one time in 2000 I went with Ezekial Lames and Justinian Suraka to do an awareness workshop in Kunua, on the mainland of Bougainville. We walked there from Hahon, about eight hours. Much of the way was through swampy land. We walked until well after dark. It's an isolated area, with families scattered and not grouped in big villages. So when we were tired of walking, there was no village nearby in which to sleep. We decided to cross one more wide, deep river and then sleep on the sand bank on the other side. The river was deeper than we thought so we had to hold hands to keep each other from floating away. When we got to the other side, we fell asleep on the sand. In the morning we woke up. We were really sore from our long walk the previous day. We looked around and got a shock to see some big saltwater crocodiles sleeping on the opposite bank. Then we spotted some swimming in the river that we had crossed the night before. We were really frightened. It was the first time I had seen this kind of crocodile. I said to the other guys, 'Let's get out of here'. So we walked away as fast as we could, and after about an hour or two we reached Kunua government station, where we held the workshop. 
The volunteers also faced physical dangers apart from those provided by wild animals and flooded rivers, as Ezekial Lames recounts (see Box 4.4).

Towards the end of phase 1 of the SCP, Leitana Nehan staff noted some of the issues that lead to an escalation of violence during the holiday season, which extends over a period of three months from November to January (LNWDA 2002c). The escalation of violence and social problems in this period was attributed to celebrations during the holiday season when many people, including public servants and school children, returning home for the Christmas holidays from other provinces of Papua New Guinea or districts within Bougainville. The teams worked during their consultations with 35 communities and 10 schools to curb the particular types of social problems that usually occur in this period. They tried to dissuade women from drinking because fights often resulted when husbands and wives both drank too much. It was noted that women also drink a lot during the festive season, which causes fights due to petty jealousies. Sexual harassment also occurred frequently when drunk men harassed women openly in public places, at dances, and even in front of relatives or family members, and this is culturally unacceptable. These incidents often resulted in fights that created disturbances in communities and among families. In addition, many families indicated that fights between fathers and sons were prevalent during this period due to a high consumption of homebrew alcohol. This scenario occurred when sons were drinking together with fathers or fathers were protecting daughters and mothers from drunken sons who would abuse them verbally or harass them physically to obtain food or money. The teams advocated strategies, such as the banning of dances and the burning of apparatus used to brew alcohol in order to minimise alcohol consumption and brewing. They hoped that these measures would contribute to minimising violence and social problems during the holiday season. In spite of these precautions, drunken men shot their wives during this period in incidents that took place in three different villages, and one woman was paralysed as a result. It is noteworthy, however, that none of these villages was actually involved in SCP. 


\section{Box 4.3 An unexpected swim Ezekial Lames}

One time in 2001 they sent us for monitoring in Daranai, in Paruparu, near the Panguna area. We got a car in Kokopau, and it was raining heavily. It rained all day. We travelled all the way without stopping in Arawa, and then went up into the no-go zone, until about five to seven in the evening we arrived in Panguna. I was dropped by the roadside and walked for about an hour to reach a village. I didn't have a torch, and it was still raining and very dark. Up there it is like a desert, because of the copper waste that flowed down. The ground is like sand. There used to be an old crane that has been dumped there. About five minutes after the crane you turn off and you can follow an old drain down the side of the cliff to a point where you can cross the river. At that time there had been a lot of rain and the river was in flood. However, I didn't realise that the river was flooded, and when I reached the end of the drain I stepped onto the sand, but it was very slippery and I slid into the river. The water carried me away. I lost my bag, which contained my sports gear and books. The current was very strong and the water was very cold as it was coming down from high in the mountains. I tried to find something to hold on to, but it was flowing very quickly. Fortunately at a bend in the river some pitpit grass was hanging over and I managed to grab it and pull myself up onto the back.

I walked back to where I had fallen in, but now I was on the opposite bank. So I had to walk further up the bank until I reached a village, Tumpu, that we had passed through before crossing the river. There I called out and some people heard me. They came out and I told them what had happened. I slept in that village and the next morning I walked to Daranai primary school to do the monitoring. After that, I had to walk up to the SDA station at Konuku. After visiting this village, I walked down for two hours and stayed overnight with another family.

The next morning I left them and walked up and down another three mountains before arriving at Paruparu station at about $1 \mathrm{pm}$. At Paruparu I visited the chiefs, teachers, students and religious leaders, and asked them how they felt about the awareness program that had been carried out, and the changes that they had noticed in the community, especially regarding homebrew consumption. There was also counselling occurring there, and I also asked them what else they wanted included in the program. Many of them felt it was a good program, especially about VAW and homebrew consumption.

These villages that the Paruparu team were working in are very remote villages, so it was hard for people to have access to stores. They would only go to Arawa about once a month. Thus they usually did not have access to soft drinks to mix with the homebrew, and as a result they were making very pure and strong homebrew. Domestic violence, rape and child sexual abuse were common in those areas during and after the crisis, and people had come to think that was just the way life was.

After the awareness they began to set up laws within the community, about how to deal with such things. For example, if a man hits a woman or child sexual abuse occurs, then the chiefs can adjudicate and impose fines of kina, pigs or shell money, and then people can reconcile. We talked about justice and peace through our IHD program. There must be justice and then peace. So if justice is not done, then there will be no peace. If we come and talk and say that we are reconciled, without justice, then there still will not be peace. They also set up some rules on homebrew. If they found anyone making homebrew, then they incurred a fine of both $\mathrm{K} 100$ and a pig, which were given to the victim, and they used the pig for a reconciliation feast. As a result, there were major changes in the community. Another result of the program in that place was that they sent twelve people down for counsellor training at Bougainville Trauma Institute. There were many people traumatised there, because the area was greatly affected by the crisis. 
In response to a question about the strategies communities involved in SCP were using to reduce alcohol related violence, the report provides examples of the following deterrents.

The schools have enforced school rules such as consumers and brewers in schools would be suspended/terminated. Community leaders have imposed fines e.g. K50 for brewing and K20 for drinking and disorderly behaviour in the village. Five men have paid fines to village magistrates (in one district) for drinking and being disorderly. Examples: bad language used and verbal harassing of women (LNWDA 2002c:n.p.).

In relation to why teams could not visit certain communities even when scheduled visits were planned, the following examples from the report provide explanations and describe the complex realities of working in a post-conflict environment where violence is simmering below the surface and events occur without warning.

Killing in a village at Tinputz prevented a workshop already scheduled to be conducted. In Bana someone died in the community, which resulted in the team not going there at all, as the ten days of mourning had to be observed. Flooding and the rainy season also prevented the teams from carrying out their awareness workshops as scheduled (LNWDA 2002c:n.p.).

By the time Leitana Nehan had reached the end of Phase 1 of SCP, the Leitana Nehan teams had altogether followed up the initial workshops in 95 communities and 35 schools. It is somewhat unclear, however, how many of these communities had also developed and carried out strategies to actively reduce violence against women and children locally. ${ }^{13}$ Leitana Nehan staff believed that the SCP had achieved its aims and objectives by covering most of the communities under the Project Workplan and that the field teams had carried out all the activities specified under the SCP Workplan as scheduled (LNWDA 2002c).

According to Crook (cited in Cox 2004:11), at the end of Phase 1, Leitana Nehan did not appear to have the organisational capacity to collect and process hard data to satisfy the monitoring and evaluation aims of its mentor NGO. This view reflects the values, attitudes and accountability emphasis of the donor agency, echoed by the mentor organisation, rather than being a real problem with SCP and Leitana Nehan itself. The following chapter, in which I describe the work 


\section{Box 4.4 A hasty departure from Kuraio Ezekial Lames}

I was sent down to Atsinima on the border between Northwest and Torokina with Alex Bunn and Steven Kuta. We caught a boat in Buka. It had a $60 \mathrm{hp}$ motor, and we travelled for about three hours. We dropped some passengers at Kuraio, and then continued to Atsinima. When we got there, we went up the river for a few minutes, then they dropped us on the bank. We walked for a couple of minutes to get to the school, where we were met by the headmaster, who was a man from Nissan. We stayed overnight and slept in the staffroom. There were many mosquitoes there. I hardly slept at all. It must have been their breeding place. So we fought the mosquitoes for ages. Then the headmaster heard us killing mosquitoes, and came and brought us some coils. The place had a low ceiling, so the coils worked well and eventually we went to sleep until morning.

The headmaster asked his son to take us to the river. It was an amazingly clear river and very cold. You could throw chains and coins into the river and they were clearly visible on the river bed. The river stones were very white, like lime. I'd never seen such clean water. So we had a bath there, and went back up to the school for breakfast. This was the first awareness that had been run in that area. We only started at $10 \mathrm{am}$, because we had to wait for people to come from far away in the centre of Bougainville Island. Those people came down with sugar cane, pineapple, muli (oranges), peanuts and all sorts of things. We ran the awareness and afterwards they gave us a meal. We were very happy and thanked them, while they thanked us for the program and the new ideas they had heard. But homebrew was really bad there. There had been many cases of rape and domestic violence in the previous months, including a woman who had been beaten to death. Just a few days before we arrived, there had been an incest case committed by a prominent person in the village. When we talked about those issues, people realised these kinds of actions were not good.

We left Atsinima and walked for about three hours along the coast, to visit another small village called Pukuito. There we met the paramount chief. The village comprises just one family. There are two temporary houses for fishing near the beach, and the permanent houses are up on the hill. They wanted the awareness to be carried out in the evening. They gave us a wild pig to eat. The chief greeted us with a bunch of peanuts, because when we arrived the chief's wife was bundling up peanuts. His brother-in-law, who is the chief's deputy and also the catechist in the village, came and greeted us with big bundles of tobacco. There were no stores there, so we couldn't find any manufactured tobacco products. Since I'm a smoker, I was quite happy. Then I needed to ask them for a page from the Post-Courier so I could make a cigarette, and they gave me one full Post-Courier, an old one.

The chief showed us around the village. First he showed us the cemetery. It was very clean, with nice flowers and a big cross. The chapel was made of bush materials and beautifully set up. We went down to the river, and he showed us upstream the place to fetch water, then further down, the place for men to wash, then the place for laundry and furthest downstream where all the rubbish ends up is the place for women to wash. Then they showed us the canoes that they use to travel up the coast.

We had a meal, before they rang the bell for chapel. Everybody came. I suggested that we conduct the awareness outside the chapel, in an open space, because we could light lots of fires for light. The chapel, even with candles, would be too dark. So we all came outside and they lit fires, and we conducted the awareness program. Afterwards we said lets drink tea and coffee, and when the chief heard there was coffee he was very happy, because he really 
liked it, and because there was none in the village. The wife brought us a big pot of boiled peanuts to eat, and they brought plenty of bananas that they cooked in the fires, and we talked and chewed betel nut and smoked and at about 3 am we all went to sleep. Just before we went to sleep, a boy cried out and it sounded like a dog. He hadn't been to school during the crisis. I nicknamed him 'Guran' which is the name of the messenger in the Phantom comics, because he was short with a big belly like an African child.

When we woke up everyone came and talked to us about the awareness, which they found really useful. They prepared three canoes, which we got in at the river bank and we paddled down to the beach. It took about half an hour to reach the sea. I was in one canoe, Steven and Alex in another, and our bags and the food they gave us were in the third. We paddled up the coast for three hours. There's no road there because the land is too steep; the mountains fall directly into the sea. We took the canoes as far as Korepovi, and then we had to walk. We met a man called Fabian, and he wanted to walk to Kuraio, where we had previously dropped passengers. We told him we were going to the same place. So he offered to help us carry our bags. We walked for more than an hour along the beach. We had to cross many rivers on the way.

We arrived in Kuraio at about 4pm. We were met by the station manager, a man named Matthew. He gave us some accommodation in a room in the priest's house. In the evening he took us to the river to wash. When we came back, two couples called out to us. They gave us some cooked taro. They also had a small canteen, and I bought some tinned fish, biscuits, sugar and three packets of rice. Unknown to us, a BRA commander, drunk and armed with a gun, had arrived in Kuraio while we were washing at the river. There was another boy at the station, who had seen us walk up the river, that heard the BRA commander asking where we were. This young boy ran up and warned us. We got back to the house without the BRA commander seeing us, but when we went to go out, the BRA commander was there. I went out first. He asked who was the leader of the team. I said that I was. He put the gun to my face, and held it there for a few minutes. But then he put the gun down. He said, 'I am going away for five minutes. When I come back if I find you here, I will shoot you.

The station manager wanted us to stay and said he would protect us. But we said we would leave, in line with Leitana Nehan's security policy. We packed our things. We found a person from Nagovisi, married to a woman from Kuraio, who had a boat, but he only had a small amount of petrol. Someone else had some petrol that he was planning to use for carrying some timber, so I offered to pay for it, since our lives were at risk. Immediately he said that was fine, but petrol was very expensive. I said that it didn't matter about the cost, because our lives were at stake. So I gave him some money and he filled up the tank. He fetched his three-year-old son, because the mother was in the garden, and we quickly pulled the boat down to the beach, hoping the BRA commander would not show up again. We made it safely to Amun and stayed overnight there. In the morning we did another awareness workshop in that village. We left Amun and walked three hours to Sipai, the Catholic Mission. We ran another awareness at the primary school there, along with the communities. We walked for about one and a half hours into a place in the bush, Mapisi Station, the district headquarters for Northwest. We slept at the primary school. We conducted three awareness workshops in Mapisi: one at the school and two in the communities, over two days. Then we walked another 30 minutes to a place called Number 10 Village. We got a boat there and followed the river down to the coast, and then back to Buka.

A few months later we did a follow-up workshop in many of the same villages. This time there were six of us, including the project officer, Benedicta Noneng. We took the boat 
to Atsinima, and then walked to Korepovi, Pukuito and Kuraio, where we only stayed a few minutes to buy biscuits and for one team member to go into the bush and take off their underwear, which was causing a rash; we never wore underwear out there because they chaffed from getting wet in the rivers and from sweat. Then we walked to Amun and Sipai, then over the mountains to Mapisi, and on to Number 10 village. We crossed a few more rivers, including one in which the water was over our heads and we had to hold our breath and carry our bags on our outstretched arms, and we rescued Quentin when he sank into the mud up to his neck, before we finally reached another village on the coast. When we told them we had walked from Atsinima, they couldn't believe it, and said that they'd never heard of anyone walking that far before. They also mentioned that no one ever crossed the last river before the village, where a young girl was taken by a crocodile only a month earlier.

carried out by Leitana Nehan in July 2003, shows that monthly reporting was relatively advanced by the middle of Phase 2 of SCP but the information was not as rich in stories and lessons from the field as it was in the Phase 1 reporting, because the mentor NGO's reporting requirements and format had changed. In many ways the stories told in Phase 1 were more useful indicators of what was actually taking place.

With an additional seven trained counsellors working with teams by the end of Phase 1, counselling services were brought closer to women in the communities, and the number of clients apparently increased in this last quarter (LNWDA 2002c). The reasons for the increase, apart from the deployment of field counsellors, included the fact that women were more willing to talk freely to counsellors who spoke their language and were from their own people. For instance, rape victims from as far back as the period 1990-97 were now coming forward for counselling (LNWDA 2002c). The deployment of field counsellors resulted in an increase in awareness about issues such as rape and domestic violence and subsequently this became evident in the counselling statistics (LNWDA 2002c). Having mobile counsellors within districts enabled Leitana Nehan to cut transport costs substantially.

\section{CONCLUSION}

Helen made following comments at the end of the SCP.

We have learned that public relations and networking with communities, authorities and NGOs on the ground has helped the SCP project to be supported well by 
communities. Through the years we were able to identify and study our target groups in different areas to gain our points of entry into the communities. Our influence, approaches and flexibility among different groups of people have gained us the support and respect of everyone in the communities under the SCP workplans. Our strength lies in the support network of volunteers who work in the 150 communities across Bougainville. The skills of staff and trainers have also contributed to the effective running of the organisation and also to project management. In the last two years of Phase 1 we feel that we have achieved our aims and objectives by promoting and contributing to the restoration of peace on Bougainville and promotion of a non-violent society (LNWDA 2002c:n.p.)

The main success of the SCP project in Phase 1 could be attributed to the design and organisation of the project and in its implementation processes, which were supported by continuous training. Specifically, the three-pronged approach employed by Leitana Nehan involved project management and counselling support from a central office in Buka; a radio program, written media coverage and the creative activities of the theatre troupe reinforcing local capacity-building; and field teams working tirelessly to engage with local community representatives and liaise with community leaders. The combined effects of these SCP support programs contributed to conflict transformation in local communities. In this sense, SCP Phase 1 was a success. SCP Phase 2 built on the foundations provided by SCP Phase 1 . The details of activities conducted by Leitana Nehan in SCP Phase 2 are discussed in the next chapter.

Counselling became a major focus for the teams by the end of SCP Phase 1. In short, the counselling needs in communities were greater than the project was designed to accommodate. The high demand for counselling, in combination with the problems associated with delivering a counselling service from the central office in Buka, as I have already discussed, prompted Leitana Nehan to seek funds to improve the counselling skills of selected team members. These were issues that Leitana Nehan had to contend with as they were planning for Phase 2.

\section{NOTES}

1 The IHD program and its approach to development are discussed in Chapter 6. It is a system used by the Roman Catholic Church to reduce social problems in the 
community. IHD is described in the Leitana Nehan proposal (LNWDA and IWDA 1999:10) as 'a holistic approach to community development that highlights the interrelatedness of social problems'.

2 The second SCP objective was 'to strengthen Leitana Nehan's ability to effectively manage and implement its program and to plan future activities by ensuring appropriate staffing and training in organisational, program and office management'.

3 The details of the partnership aspect of NGO activities and the relationships that developed between Leitana Nehan, IWDA and AusAID are discussed in Chapter 7.

4 Leitana Nehan was nominated for the Millennium Peace Prize, which it subsequently won in recognition of its peace-building work with women in Bougainville.

5 Executive Director Helen Hakena and Assistant Executive Director George Lesi both reported that the radio programs enhanced the work of the field teams. The radio program was broadcast through Radio Bougainville every Thursday at $6 \mathrm{pm}$, and there were 40 or more broadcasts per annum.

6 A number of Leitana Nehan staff and volunteer trainers underwent training in trauma counselling through the 'Family Life Team' run by the Catholic Church. Matters relating to marriage counselling were often referred to 'Family Life'. In addition, people needing legal advice were referred to the public prosecutor and private lawyers. Seven people were sent to Fiji in May 2001 for counselling training (Leitana Nehan n.d.).

7 The New Zealand High Commission funded the International Women's Day Celebrations.

8 The topics covered in this workshop for youth in Buka included: organisational structure; functions, roles and responsibilities of an organisation; characteristics of a leader; writing and working with job descriptions; communication skills, compilation of a community profile; effective networking; working well with people; setting objectives and planning activities; basic project management; and the preparation of workplans (LNWDA 2001a:8).

9 LNWDA carries out advocacy work with respect to women's rights on behalf of the silent majority of women in Bougainville. It speaks out about issues such as the fair representation of women in politics, administration and decision-making, as well as advocating to stop violence against women (LNWDA 2001a:10).

10 The topics covered in the police training included: gender sensitivity, religion, culture, socioeconomic issues and violence against women, violence as a human rights issue, domestic violence, rape, sexual harassment, the convention on rights of the child, counselling skills, legal literacy, lobbying and advocacy, all of which are relevant to objectives in SCP. 
11 BOCBHIP was concentrating mainly on health related problems that were affecting people living in and around the care centres during the Bougainville conflict.

12 The Notable Events document covered the organisation's activities between 19922003. This information was reported for the year 2000 .

13 There is a gap in reporting for 2002, a period during which all the obligations, targets and reporting for SCP Phase 1 had to be finalised to the satisfaction of the donor and mentor before SCP Phase 2 could be funded. This is common practice, in which later stages of a project are contingent on fulfilment of reporting requirements for completion of earlier stages. Unfortunately, this can too often lead to the loss of experienced staff and trainers who are forced to take up other paid work during the funding-flow interruption. 